\title{
A scalable life cycle inventory of an electrical automotive traction machine-Part II: manufacturing processes
}

\author{
Anders Nordelöf ${ }^{1}$ (D) Anne-Marie Tillman ${ }^{1}$
}

Received: 15 July 2016 / Accepted: 23 March 2017 /Published online: 9 April 2017

(C) The Author(s) 2017. This article is published with open access at Springerlink.com

\begin{abstract}
Purpose A scalable life cycle inventory (LCI) model of a permanent magnet electrical machine, containing both design and production data, has been established. The purpose is to contribute with new and easy to use data for life cycle assessment (LCA) of electric vehicles by providing a scalable mass estimation and manufacturing inventory for a typical electrical automotive traction machine. The aim of this article (part II of two publications) is to present the manufacturing data with associated collection procedures, from material constituents to complete motor. Another objective is to explain the gate-to-gate system boundaries and the principles for linking the LCI model upstream, to database data, in order to create a full cradle-to-gate dataset.

Methods Data for design and production of electrical machines has been compiled from books, scientific papers, benchmarking
\end{abstract}

Responsible editor: Zbigniew Stanislaw Klos

\section{Preamble}

This series of two articles presents a new scalable life cycle inventory (LCI) data model of an electrical automotive traction machine, available to download from the CPM database of the Swedish Life Cycle Center. Part I describes how the LCI model was established and the type of results it provides, including the underlying permanent magnet synchronous machine (PMSM) design and the structure of the LCI data model. Part II presents new primary production data and revised literature data to cover the complete PMSM motor manufacturing chain, including magnet fabrication, electrical steel production, and a comprehensive survey of an electrical motor factory. It also discusses the data collection methods and explains the selection of system boundaries and how to link the gate-to-gate inventory to the Ecoinvent database version 3.

Anders Nordelöf

anders.nordelof@chalmers.se

1 Department of Energy and Environment, Division of Environmental Systems Analysis, Chalmers University of Technology, 41296 Gothenburg, Sweden literature, expert interviews, various specifications, factory records, and a factory site visit. For the manufacturing part, new primary data was collected directly from industry, with a motor factory and a steel mill in Sweden as main contributors, and from technical literature. Other LCA publications were used, if presented in sufficient detail to be disaggregated and revised, to match the gaps of the model. The data represents the current level of technology and targets high-volume manufacturing to the largest extent possible. Also, flows crossing the system boundary have a recommended link to Ecoinvent data, or a request for an attentive selection of input data, depending on the user's object of study. A distinction was made between the regular and an extended system boundary, wherein the processing of some smaller subparts was accounted for through proposals of ready-made Ecoinvent activities for production efforts. Results and discussion An extensive new dataset representing electrical machine manufacturing is presented, and, together with the estimation of motor mass and configuration of article part I, it forms a comprehensive scalable LCI model of a typical automotive electric traction motor. New production data includes a complete motor factory, electrical steel production, and the fabrication of a neodymium-dysprosium-iron-boron $(\mathrm{Nd}(\mathrm{Dy}) \mathrm{FeB}$ ) magnet. In addition, smaller, new datasets cover the composition of silicon steel, the making of electrolytic iron, enameling of copper wire, and die casting of aluminum.

Conclusions Successful data generation required "data building" from multiple sources and access to expert support. Transparent, well-explained, and disaggregated data records were found to be crucial for LCA data validation and usefulness.

Keywords Die casting - Dysprosium - Electric - Electrical · Electrical steel $\cdot$ Inventory $\cdot$ Life cycle assessment $\cdot$ Machine . Magnet $\cdot$ Manufacturing $\cdot$ Model $\cdot$ Motor $\cdot \mathrm{NdFeB}$. Neodymium $\cdot$ Permanent $\cdot$ Production $\cdot$ Scalable $\cdot$ Silicon steel 


\section{Introduction}

\subsection{Background}

Life cycle assessment (LCA) of electrified vehicles for road transport, for example, plug-in hybrid or fully electric passenger cars, is an active research area where many case studies are conducted and published (Hawkins et al. 2012; Nordelöf et al. 2014). However, few well-populated and transparent inventory datasets have been published for electric vehicles and different electric powertrain components. This relates both to the composition of materials in the components and their production processes (Hawkins et al. 2012). Inventory data for version 3 of the Ecoinvent database, the most used and acknowledged life cycle inventory database worldwide (Weidema et al. 2013), has been published by Del Duce et al. (2016) for various components of an electric powertrain such as an electric motor and different types of power electronic devices, including production. However, some of these datasets are highly simplified, for example, the production of permanent magnets, a key subpart in permanent magnet synchronous electrical machines (PMSMs). This production is approximated with the data of aluminum production in the Ecoinvent database. In conclusion, there is a general need for more thorough investigation of vehicle production data (Del Duce et al. 2016; Hawkins et al. 2012).

Furthermore, few life cycle assessment studies of electrical machines have been published, this being especially apparent regarding focus on electric vehicle propulsion (Hernandez et al. 2017). Nevertheless, Hernandez et al. (2017) present one such study. The energy data used for motor manufacturing has been estimated from an environmental production declaration of a different type of electrical machine, applicable for industrial use (ABB 2002; Hernandez et al. 2017). In fact, ABB (2002) is also the original data source for the electric motor production data included in the Ecoinvent database (Habermacher 2011; Weidema et al. 2013; Del Duce et al. 2016). The validity of this estimation for PMSM manufacturing is difficult to assess, but the data is considered to be outdated by ABB representatives (Arnell 2012; Överstam 2013). Also, wastes and emissions from motor factories other than those coupled to energy use have not been included.

Permanent magnets are a key component in PMSMs, and neodymium-iron-boron $(\mathrm{NdFeB})$ magnets are the most common type used in electrical traction machines (Lucas et al. 2015). Pioneering data collection and compilation for such a magnet has been conducted by Sprecher et al. (2014a, 2014b). However, magnet production procedures are complex and extensive work is required to survey all process steps in detail. Both Hernandez et al. (2015a, 2017) and Sprecher et al. (2014a, 2014b) assume iron with high carbon content to be required for magnet fabrication, but unlike many other iron-containing products, elemental iron of high purity is required for the production of $\mathrm{NdFeB}$ magnets, such as electrolytic iron (Croat 1992; McCallum and Branagan 1996; Zakotnik and Tudor 2015). Hence, several processing steps are left out of both these analyses, which would possibly alter end results for the environmental load of the magnets. In addition, further advanced processing of $\mathrm{NdFeB}$ magnets is often conducted to make them suitable for automotive operating conditions, for example, adding dysprosium (Brown et al. 2002; Vaimann et al. 2013; Yan et al. 2010), which has not been covered by any of the mentioned studies.

Furthermore, production procedures for electric powertrain components are under development. They are still immature, and often take place in small series, compared to other vehicle parts (Nordelöf et al. 2014). At the same time, the relative importance of manufacturing, compared to the vehicle use phase, increases with vehicle electrification (Nordelöf et al. 2014). In conclusion, there is a lack of comprehensive inventory production data for electrical machines in automotive traction applications.

\subsection{The purpose of a scalable life cycle inventory model}

The purpose of the scalable life cycle inventory (LCI) model is to provide mass composition data and manufacturing data for a typical electrical machine design for automotive traction applications, especially for all-electric driving with a single motor. The intention is to complement the few existing datasets, and assist LCA evaluation of electric powertrains, through the generation of data for different sized machines.

The model was established as a response to the general lack of data for LCA of electrified powertrains and more specifically for electrical traction machines. It contains both design and production data and generates data on motors ranging in power from 20 to $200 \mathrm{~kW}$ and in torque from 48 to $477 \mathrm{Nm}$, i.e., from a small electric passenger vehicle up to, for example, a small electrically propelled city bus or truck (Volvo 2015). The resulting datasets represent the gate-to-gate production of the motor, from materials to complete motor, to be used as an estimate of any PMSM designed for electric propulsion, if it falls within the range for power and torque requirements for which the model is valid. Other, adjacent powertrain components, i.e., the motor controller or a gearbox, are not included. The inventory model is available as a spreadsheet file in Microsoft Excel, which can be downloaded from the SPINE@CPM LCA Database, ${ }^{1}$ together with an extensive model report (Nordelöf et al. 2016). The model report provides relevant electrical machine theory summarized for LCA practitioners, along with all the details on how the data model has been established in terms of motives for design

\footnotetext{
${ }^{1}$ Provided by the Swedish Life Cycle Center at http://cpmdatabase.cpm. chalmers.se/Scripts/sheet.asp?ActId=JT-2016-06-21-39
} 
selections and other model assumptions, and descriptions of the data collection.

Another aim has been to collect and present new manufacturing data with sufficient resolution to identify the effect of change in motor size within production, especially at the motor factory. Hence, in addition to being used as a part of the overall data model, manufacturing data can be used independently, in both cases, to conduct LCA and pinpoint key environmental issues with focus on this life cycle stage.

Finally, an important objective has been to make the model easy to use by LCA practitioners. For this reason, the manufacturing processes have been followed upstream to a point where LCI data for representative material production exist in the Ecoinvent database version 3 (Weidema et al. 2013).

\subsection{Aim and content of the article series}

The aim of this part of the publication, article part II, is to present new primary production data for PMSM motor manufacturing, electrical steel production, die casting of aluminum housings, and enameling of copper wire and to discuss data collection procedures. A description of data for permanent magnet production chain is also included, based on previously published inventory data for LCA (Sprecher et al. 2014a, b; NETL 2014a, b, 2015), but revised and updated with original data to match the neodymium-dysprosium-iron-boron $(\mathrm{Nd}(\mathrm{Dy}) \mathrm{FeB})$ type used in automotive applications. Additionally, this final article (part II) explains the selection of system boundaries and the principles behind the recommendations for linking the gate-to-gate inventory model to Ecoinvent 3 in order to create a full cradle-to-gate dataset.

As a complement, part I of the article explains the underlying electrical machine design and the general methodology and structure of the LCI data model. The design data collection and calculations are described, together with a presentation and an evaluation of the mass estimation results that the model provides.

The level of technical detail throughout both publications was selected to address a broad target group including LCA practitioners novel to electric motor terminology, as well as electrical power engineers aiming to use LCA results. For full explanations on the presented manufacturing procedures, detailed descriptions of all data collection, including assumptions and calculations, and all tables with specifications for data sources and recommendations for how to link with Ecoinvent 3 for each flow, please read the model report (Nordelöf et al. 2016).

\section{Methods}

The LCI model work entailed many important procedural and methodological considerations. The focus here is set on the manufacturing part of the model, which are the collection of raw data, the scope of the established gate-to-gate LCI including the aspect of design scaling, the use of Ecoinvent for background data, and the representativity of the study, e.g., technically and geographically.

\subsection{Data collection}

The manufacturing data included is to a large extent new original data, either collected directly from industry or from technical literature. Industry data was gathered in the form of expert interviews, site visit notes, energy audit measurements, hourly power supply figures, purchase information, permits and machine specifications, and complemented with information from instruction films, standards, and textbook descriptions. Data from other LCA publications and LCI datasets was also included when sufficient detail was presented to disaggregate, complement, and revise it to match the gaps of the model.

More specifically, motor factory data was collected for the production procedures of another electrical machine type, an induction machine, at ELMO Malmköpings Mekaniska Werkstad AB in Flen, Sweden (Walter 2015, 2016). The process flow was then adjusted to become representative for PMSM manufacturing by complementing with data from other productions sites (Hendershot 2015; Magnusson 2016) and other equipment (Willard 2015; Xue 2015). Data for electrical steel production was delivered by Surahammars Bruk AB (Lindenmo 2012, 2015), a steel mill in Sweden. Technical literature and documentation was used to establish unit processes for die casting of aluminum (Roberts 2003; Dalquist and Gutowski 2004; Heinemann 2016), the purification of iron (necessary for magnet fabrication) (Oeters and Ottrow 2012; Schlesinger and Paunovic 2010), and coating of magnet wire (enameling) (MAG 2016; Polynt Composites 2015). Data from another LCI database, the NETL (2015) unit process library, was included unrevised for the reduction of rare earth oxides to rare earth metals (NETL 2014b), in the magnet fabrication production chain.

For the fabrication of magnets, recently published data from NETL (2014a) and Sprecher et al. (2014a, 2014b), about regular $\mathrm{NdFeB}$ magnets, was used as a starting point. However, some errors were corrected and the data was reworked to become representative for an $\mathrm{NdFeB}$ magnet with dysprosium content, $\mathrm{Nd}(\mathrm{Dy}) \mathrm{FeB}$, which is suitable for automotive traction applications.

\subsection{Functional unit, system boundaries, and adaption of the inventory to the scalability of the design}

The LCI model presents a gate-to-gate LCI, for one permanent magnet electrical machine with explicit power and torque requirements, intended for vehicle propulsion. No use or end-of- 
life treatment is included. The inventory can be combined with input data for recycled as well as virgin raw materials, and the upstream system boundary is located where existing datasets for the production of materials are available in Ecoinvent version 3 (Weidema et al. 2013). The technical system boundaries of the model are shown in Fig. 1.

No specific geographic boundary has been defined for the various production steps of the model. The intention was to keep the model as flexible as possible for the user and representative on a global level. For example, all input electricity has been marked as "optional" for the user in terms of the production source or market mix. Still, the geographical location of a factory can sometimes implicate more or less automation versus handwork. In this aspect, the LCI model represents high-volume production in a factory of an industrialized country. The representativity of the data is further discussed in Sect. 2.4.

In addition, given the focus on scaling of the motor design throughout both articles in this series, it is important to point out that the modeled LCI does not take different scales of production volume or market penetration into consideration. However, efforts were made to match the design scaling properly with the manufacturing model. Hence, although the LCI model was built with conventional unit processes, the level of detail allows for a correct account of the function in each production step. For example, the energy used in welding of the rotor stack is calculated from its length, while the amount of spill from stamping in the previous step is calculated by mass. Sometimes, machining of smaller parts generate relatively more spill than large parts, for example, if they have the
Fig. 1 Overview of the technical system boundaries for the collected production data, including different main information sources and how the LCI model relates to the Ecoinvent 3 database (Weidema et al. 2013)

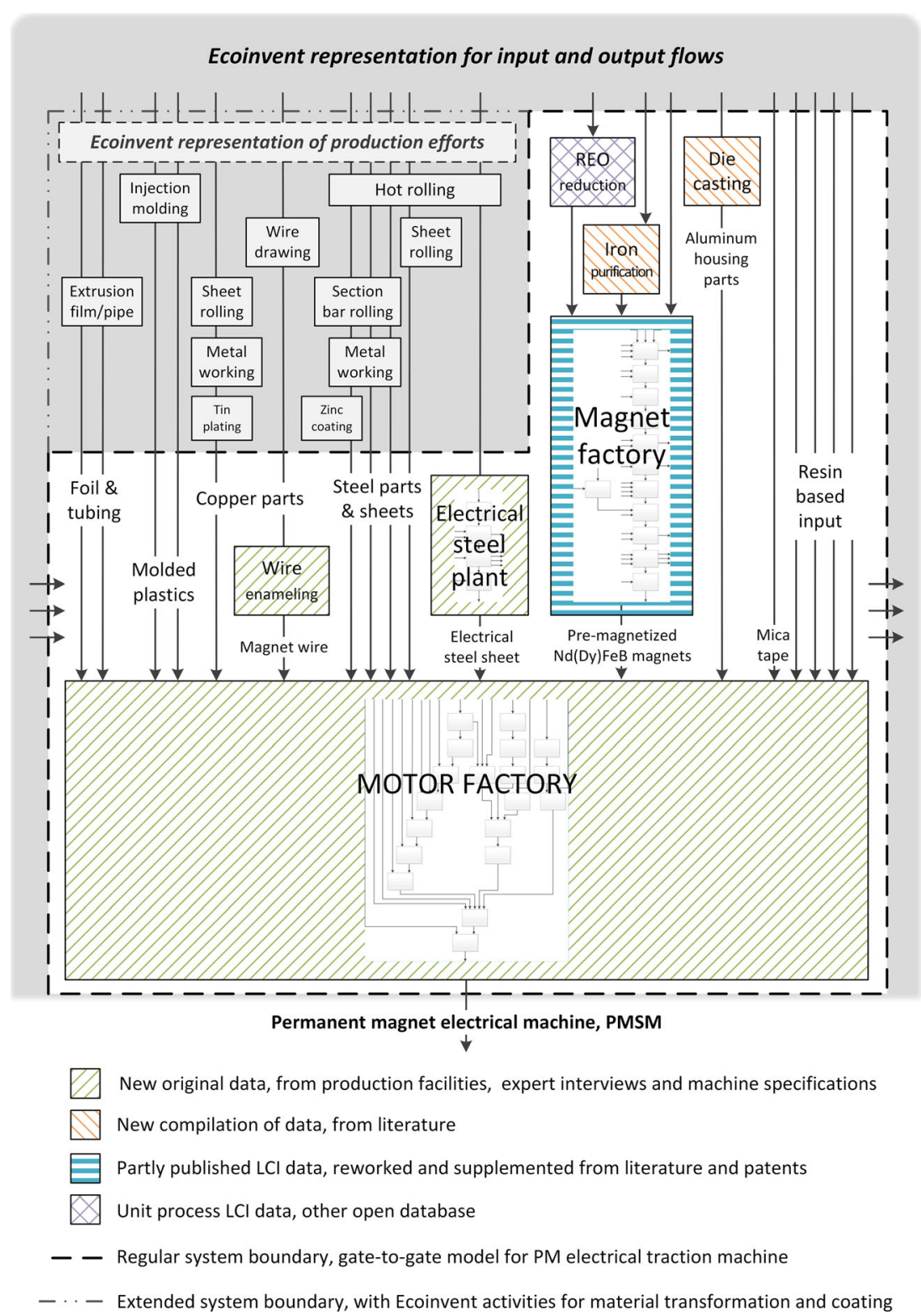


same tolerances in absolute numbers. Such an increased account of spill with decreased size of the subpart was included for the housing. As a consequence, the model often keeps track of more than one parameter in the flows between processes, for example, mass, surface area, and length in combination.

In terms of time, both design and manufacturing data have been judged as representative for the current level of technology. All data measured from industry has been collected within the last 5 years. Most textbooks, research articles, and technical reports are from the same time period or at least published within the last 10 years. However, in some cases, literature sources are older due to the lack of new data.

No transportation of goods has been included in the model. Instead, the user is expected to add subpart transportation if this is relevant to the study in which the LCI model is used.

\subsection{Linking the model to Ecoinvent}

The gate-to-gate LCI requires input of materials, energy, and processing agents, in various stages of processing. Next to the product, output is generated in the form of emissions and wastes. To make the model user-friendly, each such flow crossing the system boundary has been given a recommendation for a "linked flow" representation in Ecoinvent version 3 (marked as E3 in the model report), unless the user is called on to make a more attentive selection (marked as optional in the model file and report), for example, for the use of electricity in production.

Furthermore, as shown in Fig. 1, a distinction was made between the regular system boundary (the technical boundary referred to so far) and an extended system boundary, which encircles a set of Ecoinvent activities for material transformation and coating. These extended boundary activities are included in the LCI model file, but listed separately from the charted gate-to-gate inventory with the regular boundaries, as a recommendation for how to account for the making of several subparts from their material constituents.

The reason for this is that Ecoinvent production efforts are given in analogous form for services which reshape $1 \mathrm{~kg}$ of input raw material or semi-finished product into $1 \mathrm{~kg}$ of output product (Hischier 2007; Steiner and Frischknecht 2007; Classen et al. 2009). In the representation of metal forming, conversion of plastics, and average machine working of metals, the amount of materials removed and scrapped are included as inflow and outflow in activities, along with other auxiliaries and emissions, but not the materials and products being reshaped. Accordingly, the reference flow of the process refers to the activity and not the output product. This is also the case when the reference flow unit is expressed as a mass, e.g., the description of "hot rolling" in Classen et al. (2009). Hence, a setup featuring a separate activity list and extended system boundary was selected to avoid confusion and to separate the recommendations for Ecoinvent representation of linked flows from the actual inventory within the regular system boundaries. Users of the LCI model should be aware that these production efforts are not defined in a consistent manner. For more specifics about the differences, we refer to the original Ecoinvent reports (Hischier 2007; Steiner and Frischknecht 2007; Classen et al. 2009).

Ecoinvent coating processes for galvanization and tin plating are formulated in similar fashion to the material transformation processes (Weidema et al. 2013). They also relate only to the actual process and do not include the material being treated; i.e., the reference flow is a layer of coating of a certain thickness, expressed per surface area, and not a coated product. Hence, they have been included in the list of activities outside the regular system boundary, but inside the extended system boundary.

Lastly, the choice of linking inputs and outputs to the Ecoinvent database enabled us to make a qualitative uncertainty assessment of the inventory data according to the Ecoinvent pedigree matrix (Weidema et al. 2013) and to quantify standard deviations on the unit process level for users who wish to include uncertainty assessment based on error propagation using computational mathematics.

\subsection{Representativeness of studied manufacturing procedures}

There can be many different techniques used in manufacturing the same machine part. Several aspects are taken into consideration when selecting a specific method, such as cost-efficiency, productivity, and cycle time; geometry and strength of the part; surface finishing and material properties; and environmental hazards (Tong 2014). For example, when producing large volumes of aluminum housing parts, die casting is a suitable manufacturing method. But for lower volumes of a few hundred samples, or in the case of prototypes, cutting, drilling, milling, and turning directly from a solid block may be selected (Johansson 2015). Similarly, in large-scale production of electric motor core laminations, punching is a fast and cost-efficient method. However, punching tools are expensive, so for small production volumes, laser cutting may be more suitable.

In this inventory work, as a general approach, data representing high-volume manufacturing processes have been selected as far as possible. In some cases, mainly at the ELMO motor plant, some process steps were not found to be representative for the selected PMSM design. In such cases, manufacturing data from other sources were used and we relied on expert interviews, overviewing literature, and our own engineering judgment to achieve a reasonable level of detail, representativeness, and accuracy.

Geographically, collected data represents industrialized countries. The benchmarking literature describes of Japanese vehicle technology (Burress et al. 2008; Burress et al. 2009; Burress et al. 2011). This is also true of the properties of the magnets and recent patents concerning how they are 
manufactured (Nagasaki and Shimao 2015). For manufacturing, two of the main data sources have been Swedish production plants (Lindenmo 2012, 2015; Walter 2015, 2016), but various technical specifications and expert judgments represent European, North American, and Chinese conditions (Hendershot 2015; Larrenduche 2015; Magnusson 2016; Willard 2015; Xue 2015).

\section{The magnet production chain}

LCA data was compiled for $\mathrm{Nd}(\mathrm{Dy}) \mathrm{FeB}$ magnet fabrication. It is described below. Additionally, when using the LCI model, the user must decide how to connect input of the rare earth elements into a complete upstream production chain.

\subsection{Upstream data and the processing of rare earth elements included in the model}

The magnet production chain included in the inventory model is based on the use of rare earth elements. In natural deposits, these elements often occur as oxides (US EPA 2012). Hence, they are generally referred to as rare earth oxides (REOs), even though the outcome from extraction also includes other compound types, depending on the ore content and the separation processes (Lucas et al. 2015). Different REOs occur in conjunction and are mined together. Thus, the beneficiation and separation steps of different REOs from the same ore concentrate are typical multi-output processes in LCA terminology. In most inventory lists found, the common way to split the environmental burden from this and earlier steps in the production of REOs is to use economic allocation based on the price on each compound at a specific point in time (Althaus et al. 2007; Koltun and Tharumarajah 2014; Nuss and Eckelman 2014). But the selection of allocation procedure is an important methodological aspect in LCA. Consequently, the system boundary for the fabrication of the magnets was drawn where the relevant REOs, i.e., neodymium oxide $\left(\mathrm{Nd}_{2} \mathrm{O}_{3}\right)$ and dysprosium oxide $\left(\mathrm{Dy}_{2} \mathrm{O}_{3}\right)$, enter the production chain, in order to keep this methodological allocation decision outside the inventory model system boundaries and to hand it over to the user.

Among rare earth metals, neodymium is classified as a light element and dysprosium as a heavy element. On average, neodymium is the third most abundant of rare earth metals in present known ores, while the occurrence of dysprosium in the same ores is less than a hundred times lower (Koltun and Tharumarajah 2014). The purification stages dominate the environmental burden, and large amounts of energy, chemicals, and water are needed, especially for heavy elements such as dysprosium, which requires additional beneficiation steps compared to lighter elements (Koltun and Tharumarajah 2014; Nuss and Eckelman 2014). Toxic waste is also common (Koltun and Tharumarajah 2014).
The environmental load of the rare earth content in the electric motor can be expected to be of specific interest for a PMSM. However, Ecoinvent version 3 lacks records for $\mathrm{Dy}_{2} \mathrm{O}_{3}$, and the data for $\mathrm{Nd}_{2} \mathrm{O}_{3}$ includes a ready-made economic allocation based on fixed REO bulk prices from 2006 (Althaus et al. 2007; Weidema et al. 2013), while real prices are volatile. As a consequence, linked flows for input of REOs to the LCI model are recommended as optional, and users of the model are urged to take extra care in linking the REOs to upstream inventory data and to evaluate different options for input each time the model is used.

While dysprosium enters directly into the magnet fabrication (see Sect. 3.2) in the form of $\mathrm{Dy}_{2} \mathrm{O}_{3}$, neodymium oxide must be reduced to the pure metal form. Fused salt electrolysis is the most common industrial reduction process for light REOs, such as $\mathrm{Nd}_{2} \mathrm{O}_{3}$ (Koltun and Tharumarajah 2014; Sprecher et al. 2014a). Data for this process was collected from the NETL $(2014 b, 2015)$ unit process library. Neodymium oxide is fed to and dissolved in the electrolyte, typically a fluoride. Graphite is consumed from the anode, while pure metal deposits occur at the cathode. If the designated product is a $\mathrm{NdFeB}$ magnet, a pure iron cathode may be used to yield a high-purity neodymium-iron alloy directly from the fused salt electrolysis (Lucas et al. 2015). However, for simplicity, the dataset describes reduction into a pure neodymium metal ingot, and all iron additions were modeled in the subsequent step, since the computational result is identical. All sludge was proxied into one category and neodymium dust was specified based on Lahd Geagea et al. (2008).

\subsection{Fabrication of magnets}

The production of a sintered $\mathrm{Nd}(\mathrm{Dy}) \mathrm{FeB}$ magnet starts with the making of a mother alloy of neodymium, iron, and boron through strip casting (Sprecher et al. 2014a). Notably, unlike many other iron-containing products, elemental iron of high purity is used, e.g., electrolytic iron (Croat 1992; McCallum and Branagan 1996; Zakotnik and Tudor 2015). Boron is conventionally supplied in its elemental form (Croat 1992) or as ferro boron (McCallum and Branagan 1996; Zakotnik and Tudor 2015). Other elements than base constituents may also be added, including carbon, to boost specific properties (McCallum and Branagan 1996; Li et al. 2011; Liu and Stadelmaier 1986).

The complete magnet fabrication procedure, from strip casting to the coated and magnetized magnet, is depicted in Fig. 2. For the making of the mother alloy and the NdFeB base body, i.e., all steps down to slicing and grinding, data was gathered from the NETL (2015) unit process library and from Sprecher et al. (2014a, b), but with significant modifications and

Fig. 2 The process flow for the making of a nickel coated neodymiumiron-boron magnet with dysprosium added by means of the grain boundary diffusion method 


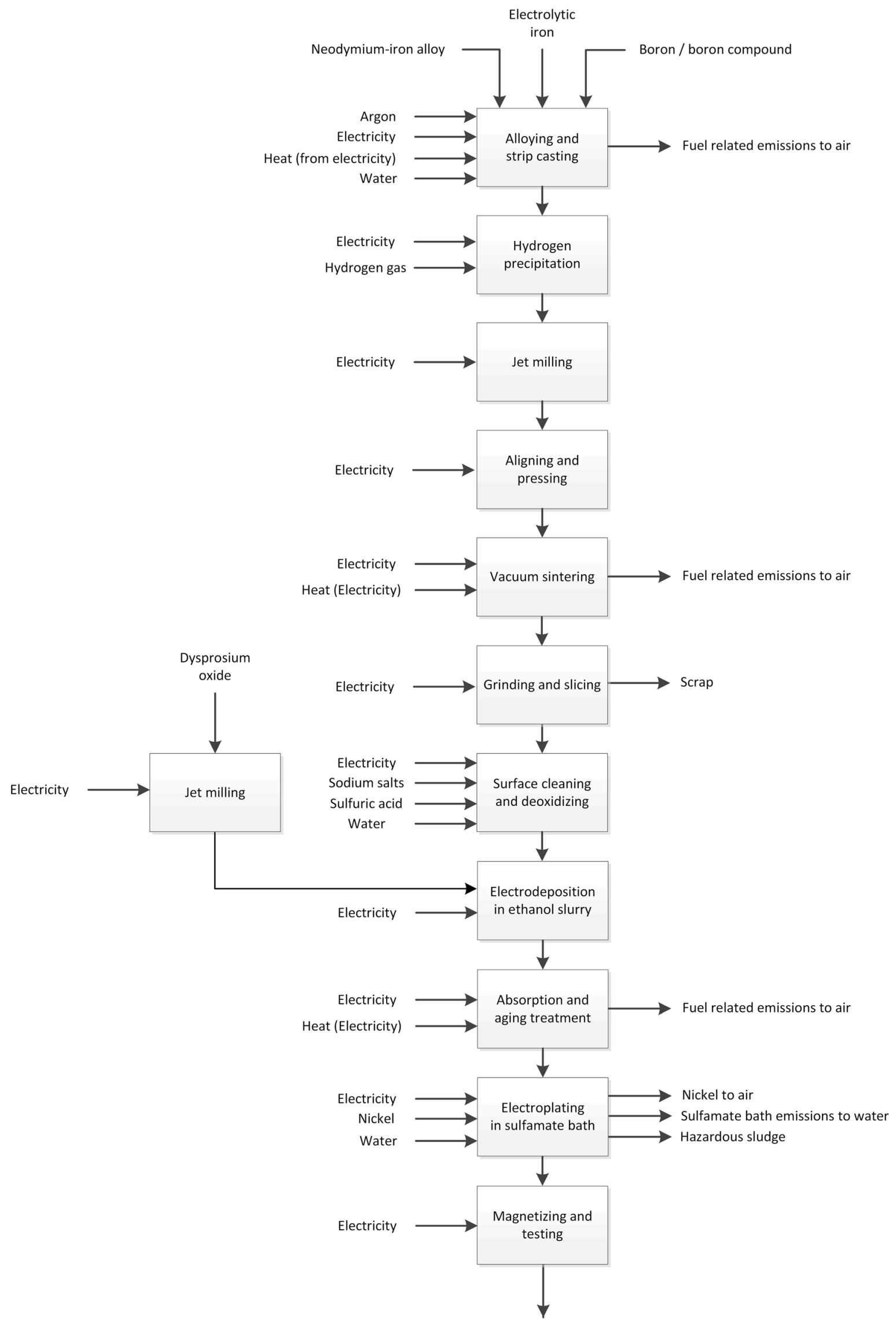

Nd(Dy)FeB magnet, nickel coated, magnetized 
corrections. As mentioned in article part I, the base body of our selected reference design matches the composition described by Sprecher et al. (2014a, b). The NETL (2014a) dataset builds upon Sprecher et al. (2014a, b), but some changes have been made. Hence, hereinafter they are jointly referred to as the "original datasets." Both use "iron pellets" as input, which is a product of iron oxide with very high carbon content (Classen et al. 2009), i.e., far from high-purity iron. Hence, data was gathered for the making of elemental iron from Oeters and Ottrow (2012), and Schlesinger and Paunovic (2010), as this was not available in Ecoinvent version 3 (Weidema et al. 2013) (see Table 1 (a)). Boron carbide was chosen as the source of boron, based on Chen et al. (2006).

Table 1 Process inputs, emissions, and wastes in the form of unit processes established for the magnet production in the $\mathrm{Nd}(\mathrm{Dy}) \mathrm{FeB}$ PMSM LCI model

\begin{tabular}{ll} 
(a) Production of $1 \mathrm{~kg}$ of electrolytic iron & \\
Process input & Amount per kg \\
Unalloyed steel & $1.1 \mathrm{~kg}$ \\
Electricity & $2 \mathrm{kWh}$ \\
Solid waste & Amount per kg \\
Sludge ${ }^{\mathrm{a}}$, dry content & $0.25 \mathrm{~kg}$ \\
(b) Production of $1 \mathrm{~kg}$ of Nd(Dy)FeB nickel coated magnet \\
Process input & Amount per kg \\
Electrolytic iron & $830 \mathrm{~g}$ \\
Boron carbide & $15 \mathrm{~g}$ \\
Neodymium & $310 \mathrm{~g}$ \\
Nickel & $11 \mathrm{~g}$ \\
Dysprosium oxide & $91 \mathrm{~g}$ \\
Electricity, sintering & $8.4 \mathrm{kWh}$ \\
Electricity, other & $5.6 \mathrm{kWh}$ \\
Hydrogen & $0.6 \mathrm{~kg}$ \\
Caustic soda & $1 \mathrm{~g}$ \\
Sulfuric acid & $1.4 \mathrm{~g}$ \\
Water & $6 \mathrm{~kg}$ \\
Emissions to air & $\mathrm{Amount}$ per kg \\
Nickel & $4.2 \mathrm{mg}$ \\
Emissions to water & $\mathrm{Amount}$ per kg \\
Nickel sulfamate & $5.1 \mathrm{mg}$ \\
Solid waste & $\mathrm{Amount} \mathrm{per} \mathrm{kg}$ \\
Neodymium-iron-boron scrap & $200 \mathrm{~g}$ \\
Sludge & , dry content \\
\hline
\end{tabular}

For further details on specific sources per flow and recommended linked flows in Ecoinvent version 3, please read the model report (Nordelöf et al. 2016)

${ }^{a}$ Assumed to be ferrous chloride

${ }^{\mathrm{b}}$ Consists of $23 \%$ nickel

${ }^{\mathrm{c}}$ Consists of $97 \%$ nickel sulfamate and $3 \%$ nickel chloride and contains $24 \%$ nickel in total
In the alloying and strip casting process, metal ingots or powders are melted together and then separated into flakes. Two pulverization steps follow: first, hydrogen precipitation where the flakes crack into a fine powder using hydrogen gas and, second, jet milling, where the powder is milled further in a grinding chamber. The resulting powder has a mean particle size around $5 \mu \mathrm{m}$ (Brown et al. 2002). The powder is aligned with a strong magnetic field and compressed in a mold (Brown et al. 2002; Lucas et al. 2015). The compacted cake is vacuum sintered above $1000{ }^{\circ} \mathrm{C}$ with the effect that the particles are bonded into a solid structure and the magnet base body shrinks as the density roughly doubles (Fang 2010). Next, the magnet body is attained through grinding, slicing, and drilling.

In modern procedures, it is reasonable to assume that the heating processes in magnet fabrication are conducted in electric furnaces, based on indirect resistance or induction (McCallum and Branagan 1996; Fang 2010). Hence, unlike the original datasets (NETL 2014a; Sprecher et al. 2014a, b), all heating processes were modeled as electric, and auxiliary electricity was added for the strip casting process. Energy consumption figures for vacuum sintering were taken directly from Sprecher et al. (2014b), because NETL (2014a) use an average energy use for vacuum sintering and iron ore sintering (Classen et al. 2009), which was not found to be representative. Additionally, both employed original datasets (NETL 2014a; Sprecher et al. 2014a, b) included emissions to air based on iron ore sintering, which were not included in this inventory. In fact, there are major differences between the sintering of iron ore into iron oxide sinter and vacuum sintering of a metal alloy consisting of an essentially pure element mixture. All air emissions from iron oxide sintering relate to the ore feed content and the burning of coke, with some additional dust created during handling and crushing (IPPC 2001). Instead, vacuum processing is often used for sintering of metals as it avoids adding impurities from a surrounding atmosphere (Fang 2010). Hence, emissions from both alloying and sintering of $\mathrm{NdFeB}$ magnet bodies can be assumed to derive from the process providing the heat, either the burning of a fuel or the production of the electricity consumed, rather than the process itself.

Subsequently, the magnet is cleaned to prepare for the dysprosium addition and the final coating (Schlesinger and Paunovic 2010). The most novel method for applying dysprosium to the base body to improve the NdFeB magnets' coercivity and heat resistance is referred to as grain boundary diffusion (Lucas et al. 2015; Vaimann et al. 2013). The main principle is to apply a dysprosium carrying substance as a powder coating on the base body of the magnet and put it through two subsequent heat treatments, first in an absorption treatment and then in an aging treatment, so that the dysprosium diffuses into the neodymium-rich phase between the grains of the magnet body, but not into the grains. For this 
reason, the temperature is preferably kept close to but below the sintering temperature. This is also important in order not to deform the magnet body structurally or alter the achieved magnetic alignment (Nagasaki and Shimao 2015). Another challenge is to achieve a uniform coating coverage before heating, but this can be overcome by electrodepositing fine dysprosium oxide powder on the magnet body (Nagasaki and Shimao 2015).

The process description and data for the grain boundary diffusion of dysprosium into the base magnet body was gathered from Nagasaki and Shimao (2015) and Suppan et al. (2015). It was combined with a theoretical description of electrodepositing described in Schlesinger and Paunovic (2010) to calculate the energy use directly from Faraday's law for electrolysis resulting in a $0.3 \mathrm{kWh} / \mathrm{kg}$ magnet of ordinary grid electricity. The energy used for jet milling of the dysprosium oxide to proper particle size was taken from Sprecher et al. (2014b). Dysprosium oxide is milled to a particle size below $10 \mu \mathrm{m}$ and then mixed with ethanol to form a slurry bath before it is deposited by means of electricity.

The final coating, added to protect against corrosion, is also applied by electroplating the magnet body, this time in a nickel sulfamate bath. Electroplating data was gathered from Moing et al. (2009), with some simplifications. For example, all sodium salts used for cleaning (sodium carbonate, trisodium phosphate, sodium gluconate, and caustic soda) were proxied as caustic soda, this being the largest constituent. Pure nickel is dissolved at the anode and plated onto the magnet, acting as the cathode. Several rinsing steps lead to water emissions from drag-out losses, but there can also be some evaporation of nickel to air (Moing et al. 2009). The nickel coating thickness was set to $15 \mu \mathrm{m}$ corresponding to $1 \%$ of the total magnet mass. Faraday's law for electrolysis (Schlesinger and Paunovic 2010) was used again to scale the electricity used in line with the deposited mass.

Finally, all magnets must be magnetized, either before they are sent-off to the motor factory (premagnetization) or after they have been mounted into the rotor (postmagnetization). The magnetization process itself is very quick. A strong magnetic pulse of $6 \mathrm{~T}(4-8 \mathrm{~T})$ is applied during less than a millisecond (Sprecher et al. 2014a; Lucas et al. 2015).

To summarize this section, Table 1 (b) shows the resulting inventory for the magnet fabrication.

\section{Manufacture of metal subparts, plastics, and insulation}

The inventory model includes the production of all subparts in the scalable PMSM. This chapter describes the making of all other parts, in parallel with the magnets, in the steps before they arrive to the motor factory.

\subsection{General processing of steel and copper}

All making of steel parts entering the motor factory, except for the final electrical steel sheet processing, was modeled with activities which are available ready-made in the Ecoinvent 3 database to account for metal working, forming, and coating (Steiner and Frischknecht 2007; Classen et al. 2009; Weidema et al. 2013). These activities were included in the LCI model within the extended system boundary, but outside the regular system boundary, as explained in Sect. 2.3. For example, hot rolling, which is an intermediate steel making process where the ingots, blocks, and beams from raw steel making are treated to enhance durability, shock resistance, and tensile strength, was applied on all types of steel alloys.

In summary, several rolling and machining activities were selected to roughly match the making of different steel parts, i.e., steel coils, bearings, plates, bolts, nuts, and washers, along with the rod for making the shaft at the motor factory. Figure 3 shows an overview of the recommended Ecoinvent 3 production efforts for steel parts, which were listed in the LCI model. Additionally, plates, nuts, bolts, and washers are then galvanized, as accounted for in a separate zinc coating activity.

Similarly, the making of copper wire for the conductors and copper lugs in the connectors of the terminal block also refer to predefined production activities in Ecoinvent 3 (Weidema

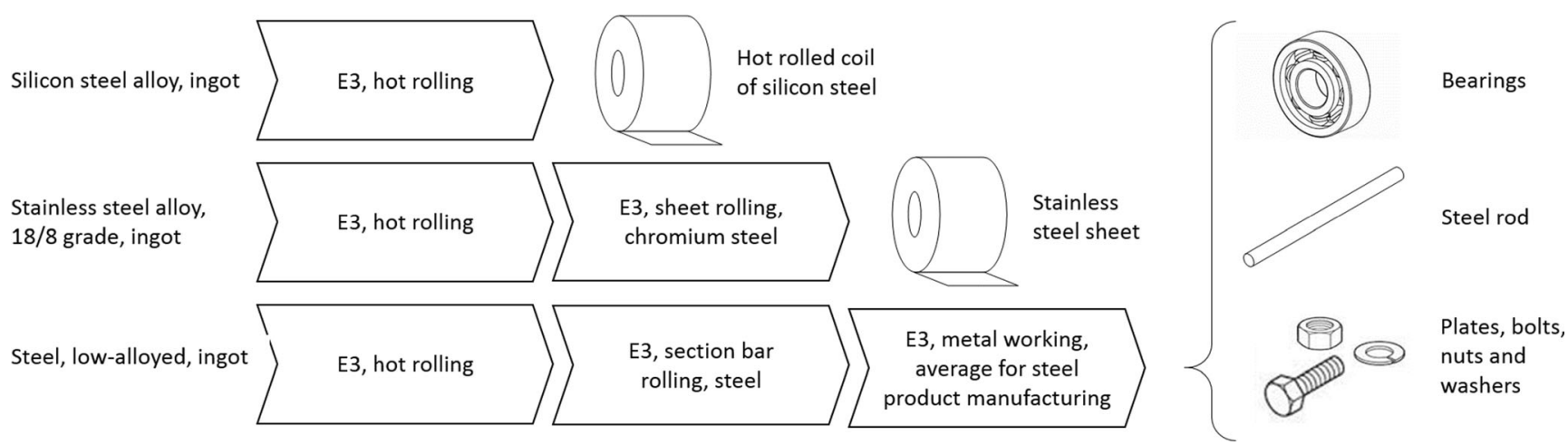

Fig. 3 Production efforts for steel available in Ecoinvent 3 (Weidema et al. 2013), specified per kilogram of material being processed. The processes have been included within the extended system boundary of the LCI model to account for general processing of steel parts 
et al. 2013). Copper wire drawing includes rolling, cutting, and repeated pulls though different drawing dies to reduce the cross section to the desired size (Classen et al. 2009). Cable lugs are made by cutting and forging copper tubes, in turn made by rolling and drawing. Lugs are tin coated. The complete production was modeled by combining rolling and machining activities, and adding a tin plating process.

\subsection{Electrical steel making}

The starting point for making electrical steel is high-quality hot rolled coils of silicon steel, as described in Sect. 4.1. However, prior to hot rolling, crude steel is alloyed into silicon steel, containing on average $2 \%$ silicon and $0.4 \%$ aluminum (Lindenmo 2015), during the ladle processing of liquid steel (Ghosh 2000). Hence, it was accounted for as an add-on process within the making of unalloyed steel, as available in Ecoinvent 3 (Weidema et al. 2013). Suitable amounts of aluminum wire or ingots and granulates of ferrosilicon are mixed into the liquid steel, beyond the standard use of ferrosilicon for deoxidation (Ghosh 2000; Lagneborg and Waltersson 2004). Typical ferrosilicon (with $75 \%$ silicon) is a major source of heat in the mixture, since it reacts exothermically (AMG Vanadium 2015), and this was assumed to cover for the melting of both added constituents, without the need for a supply of additional heat energy in the ongoing steel making process. Table 2 (a) summarizes the process inputs.

At the electrical steel plant, the incoming silicon steel coils are pickled, cold rolled into the desired thickness, and annealed to receive the desired "non-oriented" magnetic properties. Also, sheets are commonly coated with some insulation material. Primary data for this process flow, shown in Fig. 4, was gathered from Surahammars Bruk $\mathrm{AB}$ (Lindenmo 2012, 2015). Electricity is required to drive the rolling mill, but also ventilation, lighting, and general machinery. Annealing is executed in a propane fired furnace. Pickling requires sulfuric acid in a bath. After passing the bath, sheets are rinsed with water. Quicklime is used to neutralize the rinsing water, remaining acid on the steel surface and sometimes complete expended pickling baths (Lewis and Boynton 1999; The National Lime Association 2015). The result is a sludge, which must be disposed of, usually to a landfill. However, the pickling bath may also be used further in other industrial processing, e.g., in making precipitation chemicals. In this case, it was assumed that the pickling bath is not neutralized to become sludge, in line with procedures at Surahammars Bruk AB (Lindenmo 2015). Instead, it was regarded as a by-product of no value, and all the environmental load has been allocated to the electrical steel sheets, these being the main product. Table 2 (b) shows the resulting unit process inventory for the electrical steel plant.
Table 2 Process inputs, emissions, and wastes in the form of unit processes established for the production of parts in the $\mathrm{Nd}(\mathrm{Dy}) \mathrm{FeB}$ PMSM LCI model

(a) Alloying of $1 \mathrm{t}$ of silicon steel

Process input
Unalloyed steel
Ferrosilicon
Aluminum

(b) Production of $1 \mathrm{t}$ of electrical steel sheets

Process input

Silicon steel, hot rolled

Electricity

Propane/LPG

Sulfuric acid

Rolling/lubricating oil

Quicklime powder

Phenolic resin

Emissions to air

Carbon dioxide

Nitrogen oxides

Sulfur oxides

Solid waste

Steel scrap

Sludge ${ }^{\mathrm{a}}$, dry content

(c) Die casting of $1 \mathrm{~kg}$ of aluminum

Process input

Aluminum

Heat, from natural gas

Electricity

Lubricating oil

Emissions to air ${ }^{\mathrm{b}}$

Aluminum

VOC

Solid waste

Waste aluminum ${ }^{\mathrm{C}}$

(d) Enameling $1 \mathrm{~kg}$ of magnet wire

Process input

Copper wire, uncoated

Liquid enamel, polyester share

Liquid enamel, xylene solvent share

Electricity

Emissions to air

Xylene

\begin{tabular}{|c|}
\hline Amount per $1000 \mathrm{~kg}$ \\
\hline $979 \mathrm{~kg}$ \\
\hline $27 \mathrm{~kg}$ \\
\hline $4 \mathrm{~kg}$ \\
\hline Amount per $1000 \mathrm{~kg}$ \\
\hline $1140 \mathrm{~kg}$ \\
\hline $630 \mathrm{kWh}$ \\
\hline $12 \mathrm{~kg}$ \\
\hline $19 \mathrm{~kg}$ \\
\hline $0.4 \mathrm{~kg}$ \\
\hline $0.8 \mathrm{~kg}$ \\
\hline $1 \mathrm{~kg}$ \\
\hline Amount per $1000 \mathrm{~kg}$ \\
\hline $36 \mathrm{~kg}$ \\
\hline $0.1 \mathrm{~kg}$ \\
\hline $60 \mathrm{mg}$ \\
\hline Amount per $1000 \mathrm{~kg}$ \\
\hline $114 \mathrm{~kg}$ \\
\hline $3.3 \mathrm{~kg}$ \\
\hline Amount per kg \\
\hline $1.06 \mathrm{~kg}$ \\
\hline $10.8 \mathrm{MJ}$ \\
\hline $2.6 \mathrm{kWh}$ \\
\hline $20 \mathrm{~g}$ \\
\hline Amount per kg \\
\hline $0.4 \mathrm{~g}$ \\
\hline $1 \mathrm{~g}$ \\
\hline Amount per kg \\
\hline $60 \mathrm{~g}$ \\
\hline Amount per kg \\
\hline $0.96 \mathrm{~kg}$ \\
\hline $43 \mathrm{~g}$ \\
\hline $23 \mathrm{~g}$ \\
\hline $0.5 \mathrm{kWh}$ \\
\hline Amount per kg \\
\hline $23 \mathrm{~g}$ \\
\hline
\end{tabular}

For further details on specific sources per flow and recommended linked flows in Ecoinvent version 3, please read the model report (Nordelöf et al. 2016)

${ }^{\mathrm{a}}$ Consists of $60 \%$ calcium sulfate $\left(\mathrm{CaSO}_{4}\right)$ and $40 \%$ ferrous hydroxide $\left(\mathrm{Fe}(\mathrm{OH})_{2}\right)$

${ }^{\mathrm{b}}$ Emissions from the burning of natural gas has not been included and must be accounted for separately

${ }^{\mathrm{c}}$ Not recovered for recycling, but instead removed in mixture with other fine scrap and dirt during cleaning 


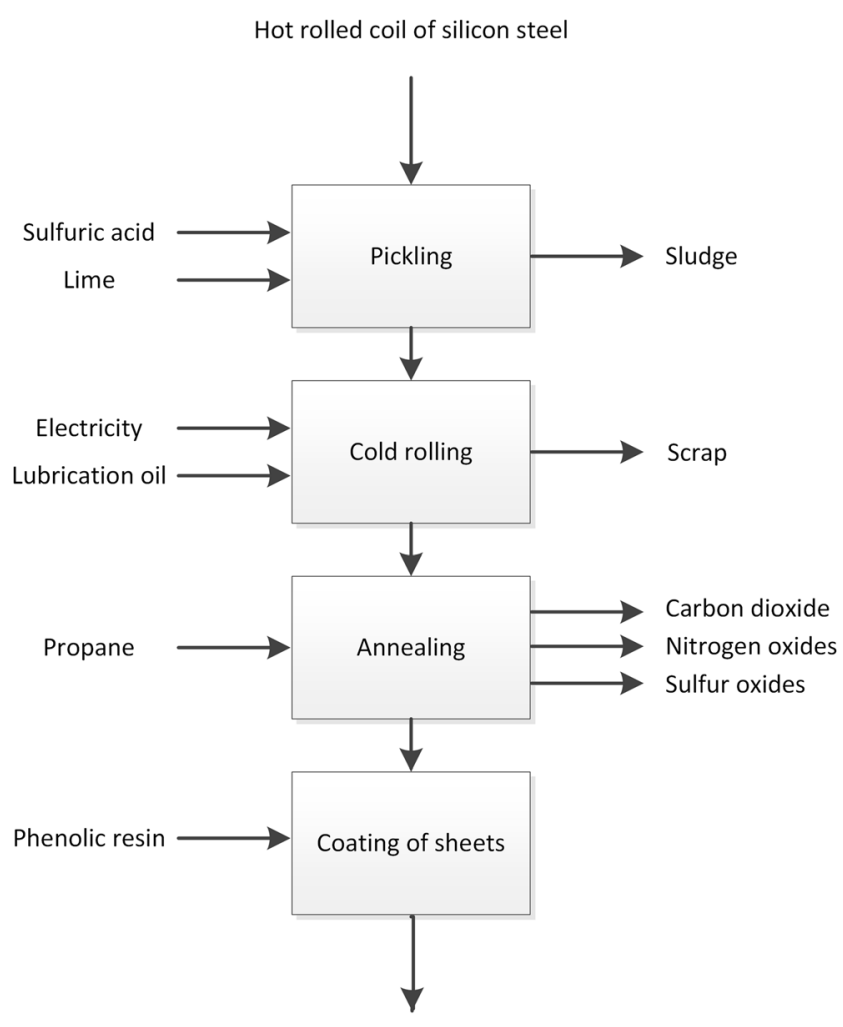

Electrical steel sheet

Fig. 4 Electrical steel plant process flowchart

\subsection{Aluminum die casting}

Casting is a common method for producing aluminum shapes such as cylindrical housings and endbells (Tong 2014). Complex shapes can be produced with high efficiency and at low cost, especially in large series production. Molten metal is poured or pressed into a die. Commonly, the term "die casting" refers to the use of a permanent steel mold, i.e., a reusable die which can last up to a million castings (Dalquist and Gutowski 2004). Data for a unit process was compiled from Roberts (2003), Dalquist and Gutowski (2004), and Heinemann (2016) (see Table 2 (c)). The making of the mold was not included, since it was assumed to have a negligible contribution per part in large-scale production.

Major steps in the die casting process are die preparation, metal preparation, casting, and finishing. The metal melting is conducted using a small natural gas furnace, whereas other processes use electricity (Heinemann 2016). Direct emissions mainly derive from the burning of natural gas (not included in Table 2 (c), but both preparation and casting also release fumes of aluminum, as well as VOC emissions from oilbased lubricants (Dalquist and Gutowski 2004). Metal scrap and dross are to a large extent recovered and remelted within the facility. However, some dross and filings go to waste as unrecovered dirt (Heinemann 2016).
4.4 Preparation of parts with coatings, plastics, and other insulation materials

The difference between pure copper wire and magnet wire, i.e., the conductors in the stator windings (described in article part I), is the enamel coating layer. A liquid enamel film is applied when copper wire is pulled through a nozzle in a dedicated enameling machine (Brenn et al. 2012). Next, the coated wire is dried and cured in an electric oven where solvents evaporate while chemical reactions inside the film lead to cross-linking of the enamel polymers (Czaputa 2012). Almost half of the heat necessary is released from the exothermic curing reaction (Czaputa 2012). Electricity consumption data for enameling was gathered from MAG (2016) and the composition of the liquid enamel from Polynt Composites (2015). Results are shown in Table 2 (d).

Two subparts in the machine design contain polybutylene terephthalate (PBT) plastics, the resolver, and the terminal block. In both cases, injection molding is a common method used to fabricate various shapes from plastic granulates. Extrusion is another, even more common way to make plastics (Hischier 2007). For the electric motor, this method is used for the production of the polyethylene terephthalate (PET) slot liners and separators, as well as the soft cross-linked silicone rubber (elastomer) insulation for the phase conductors. Injection molding and extrusion of plastic and elastomer parts were accounted for within the extended system boundaries of the model, in the form of Ecoinvent 3 production activities (Weidema et al. 2013). Similar to the material conversion processes for metals, these activities can be viewed upon as reshaping services with a reference unit of $1 \mathrm{~kg}$. However, unlike plastics, where most energy use during extrusion is coupled to the heat necessary to plasticize granulates, silicone is extruded at low temperature (Hischier 2007; Leoni 2014). On the other hand, heat is required for the silicone cross-linking process (Leoni 2014). Hence, the selected Ecoinvent 3 activity was still found to be a relevant approximation.

With the exception of PBT, the resolver is built with hand wound magnet wire and electrical steel. Electrical steel losses were accounted for, but energy use for punching was found to be negligible. The machine design also contains synthetic products, such as the stator impregnation resin, the magnet fixation adhesive, the nylon lacing cord, and the housing varnish. For all these materials, it was assumed that no further processing is necessary other than what is included in the recommended linked flows of Ecoinvent 3 reference products (Weidema et al. 2013). However, in particular, the mica tape used for the phase insulation of the stator windings requires several additional fabrication steps, compared to its input material composition. Still, for simplicity, and given the very low contribution to the overall machine mass, the processing of the mica tape beyond the material constituents was investigated but neglected in terms of data inclusion. 


\section{The motor factory}

\subsection{Overview and building services}

Figure 5 shows a process flow representative for a PMSM motor factory. Overall, the flowchart was established based on a site visit made to ELMO Malmköpings Mekaniska Werkstad AB in Sweden (Walter 2015), complemented by a description of how to mount interior permanent magnets into the rotor from Motorsolver LCC in Kentucky, USA (Hendershot 2015). Moreover, the steps for splining and surface hardening of the shaft were included based on the expertise of Låftman (2012). Encompassed processes have been numbered in steps from 1 to 19 (see Fig. 5) to simplify referencing to specific processes in the following text. No tables with unit process data will be presented throughout this chapter, as it would be too detailed for the scope of the article. Neither will any aggregated gate-to-gate inventory be reported for the motor factory, since a key feature of the data gathered here is the matching with the scaling of the motor size, as described in article part I. Instead, Sect. 5 provides a description of the different processes and explains how various sources were combined to establish this part of the LCI model inventory.

In summary, in step 1, electrical steel sheets are turned into laminations; in step 2, the stator core is built; in steps 3-5, the winding is installed in the stator and secured with insulation; in step 6, the stator package goes through impregnation of slots and end-windings; in step 7, conductors are furnished with connector lugs; in steps $8-10$, a splined shaft is made from a uniform steel rod; in step 11, the rotor core is built in conjunction with the installation of segmented magnets; in step 12, the rotor end-plates are made from a sheet of stainless steel; in steps 13-14, the rotor package is brought into one piece and balanced; in steps 15-17, die cast housing parts are prepared for assembly together with the terminal block; in step 18 , the machine is assembled with all subparts; and, in step 19, the exterior of the housing is painted before the motor is ready to leave the factory.

Additional to the specific manufacturing processes presented in Fig. 5 are several basic functions necessary to operate a motor factory, referred to as technical building services. These require energy, and may cause emissions, relating to the total activity and size of the motor plant. Thus, the environmental load carried by each electrical machine produced must be decided by means of allocation. Typical building services include heating or cooling, ventilation, lighting, and different types of auxiliary energy use, e.g., electricity for compressed air and computers for various work and tasks.

An assessment of technical building services was conducted for the ELMO plant and found to be fully based on electricity (Walter 2016). Measurements from an energy audit (Karlsson 2013), and hourly power supply figures representing 2013, were used as input (Walter 2016). Startup and standby of machinery, as well as general use of compressed air for pneumatic control and blowing operations, were included. It was found that more than half the electricity used at ELMO during 2013 was coupled to building services, which is in line with other references (Gutowski et al. 2006; Bonvoisin et al. 2013). Furthermore, the ELMO plant produces various metal components in addition to electrical machine manufacturing. Seventy percent of the electricity coupled to technical building services were allocated to electrical machine manufacturing, based on the general use of compressed air in relation to the two product types as being the best available indicator (Walter 2016). Another important assumption was that the plant runs at current maximum capacity, about five times higher than the actual production in 2013, and that the overall time to produce one electrical machine, gate-to-gate, is roughly the same regardless of machine type, specific design, and size. The allocation was then based on production time, and each PMSM unit was assigned the same load for technical building services regardless of size, roughly $9 \mathrm{kWh}$ of electricity per unit.

\subsection{Producing the stator package}

Electric machine manufacturing begins with the punching of stator and rotor laminations from the same electrical steel sheet (process 1 in Fig. 5). The process is fast and efficient but requires the making of an expensive stamping tool, designed to provide the desired geometry for the laminations. Next, in process 2, stator laminations are stacked, pressed, and joined together on a fixture, often through welding (Walter 2015). Rotor laminations continue on to process 11. Energy use for punching was based on expert estimations for suitable settings of the ELMO stamping equipment to make the small reference machine laminations (Walter 2015). The same energy use per kilogram of electrical steel was used for the large reference machine, matching a higher power load required for a larger cutting shape. Electricity and argon use for stacking and welding of the stator were gathered from Walter (2015). Scrap losses for processes 1 and 2 were calculated by means of geometry and typical loss information.

Data for processes 3-5, i.e., installing the windings, including slot liners and separators, phase insulation and phase conductors, and the pressing of the end-turns, was gathered from ELMO (Walter 2015) and combined with lacing machine data from Ningbo Nide (2014). Slot liners are cut, shaped, and rapidly inserted into the stator by a machine. The same machine is used to cut and shape separators, which are inserted later. For the windings, magnet wire is wound into coils, which are mounted onto a fixture matching the number of slots in the stator. The coils are then pulled through the stator into the slots, inside the slot liners. In two-layer windings, the deepest layer is pulled through first. Slot separators are placed 


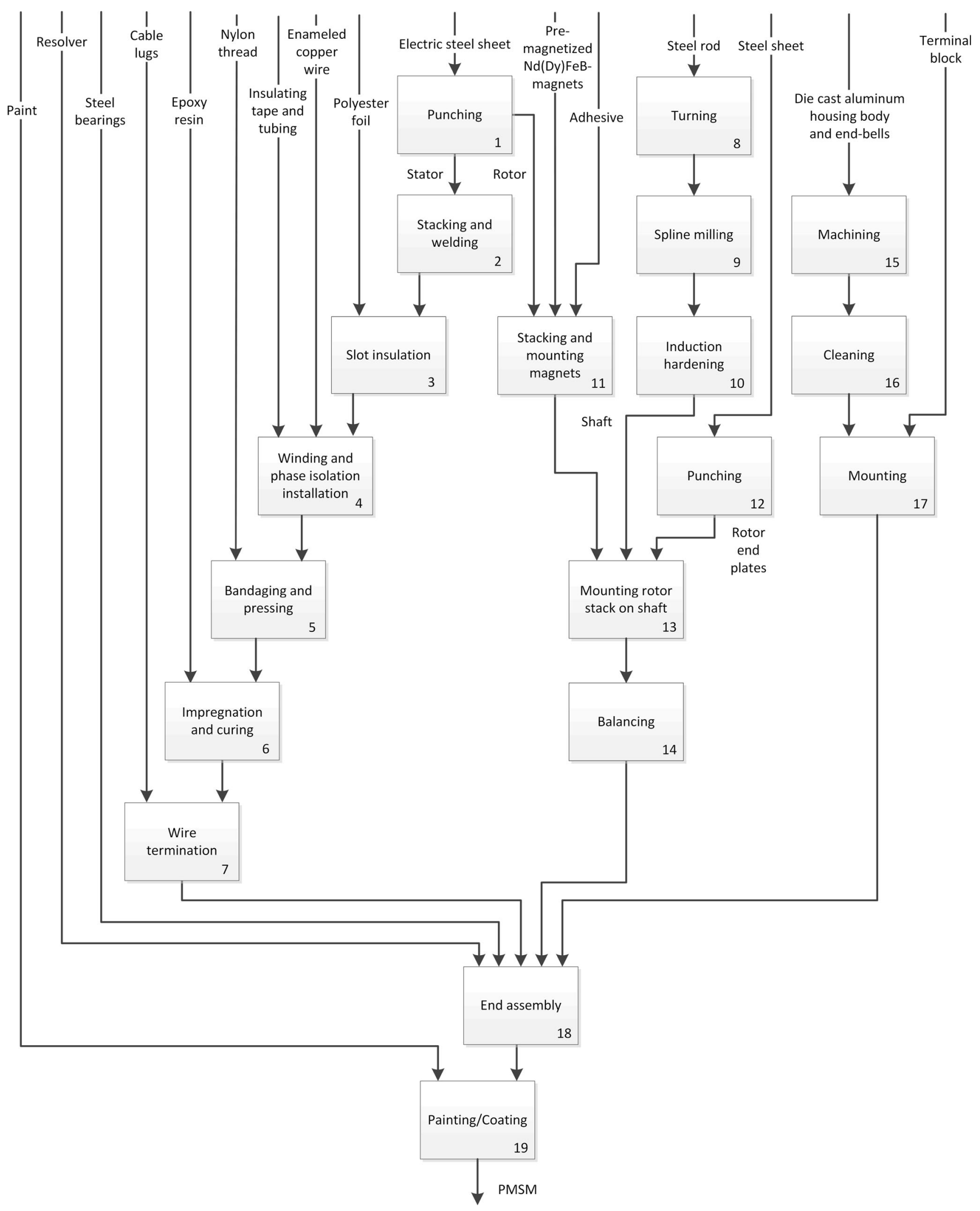

Fig. 5 Motor factory process flowchart for a PMSM, divided into 19 processes 
in the slots and isolation tape is applied to the end-turns of the installed layer, by hand. Phase conductors are prepared by pinching or soldering ready-made insulated cables to the coils or by threading tubes over the magnet wire conductors extending from the coils. In order to secure the windings, end-turns are laced with a thread and then machine pressed. Lacing and pressing account for most of the electricity used in processes 3-5. It was assumed that there were no losses of phase conductor insulation and nylon thread.

Overall, the impregnation of the stator windings is one of the most energy-demanding processes in the motor factory (Karlsson 2013; Walter 2015) due to the need for oven heating. Several methods are possible, e.g., casting, dipping, and trickling (Richnow et al. 2014; Tong 2014). Trickling is an extensively used method, well suited for the studied motor design. Resin is poured or sprayed onto the winding in a fine jet, often when the stator is rotating and slightly inclined, and then drawn into the cavities of the slots and end-windings by capillary action. The amount of resin can be accurately managed without dripping losses and the processing time is relatively short, although the investment cost is high because advanced automation equipment is required. Data for electricity use of trickling was averaged out among nine machines of two different types (Broomfield 2014a, b; Ningbo Haishu Nide 2014; Willard 2015). The length of zones for preheating, trickling, gelling, and curing were estimated from machine drawings and combined with the heating requirements of the resin (Larrenduche 2015) to estimate the cycle time. As an approximation, heating all zones up to their rated maximum temperature was set to require full power consumption of the machine, including auxiliaries such as ventilation, and related linearly. Finally, 5\% of the liquid epoxy resin base content were assumed to evaporate in the form of white smoke of hydrocarbons from the curing process (Larrenduche 2015).

The loading capacity of the trickling machines was found to relate primarily to the stator diameter yielding two fixed values for electricity use in impregnating the two reference machines, 0.35 and $0.46 \mathrm{kWh}$. As a comparison, the dip and batch bake procedure at ELMO, which is not dependent on the stator diameter in the same way, requires about $2 \mathrm{kWh}$ per stator (Karlsson 2013; Walter 2015).

Before final assembly, in process 7 of Fig. 5, the main phase conductors, i.e., all wire branches joined per phase, must be crimped with copper lugs to enable connection to the terminal block (Walter 2015). Crimping is a form of resistance welding, where wires have been stripped and placed compactly inside each lug. The metal parts anneal and join strongly owing to high temperature. Energy use and copper scrap quantity were calculated from information provided by Amada Miyachi (2015), TES Vsetín (2015), and Walter (2015).

\subsection{Building the rotor package}

The making of the shaft in processes $8-10$ of Fig. 5 is one of the three parallel subpart flows necessary to build the rotor package. Shaft machining procedures vary with the design, e.g., if hollow or solid and the type of mechanical joint. Nevertheless, the primary processing step comprises turning and forming the incoming steel rod into the desired shaft (Junker 2012). Other steps involve drilling and milling with high-precision computer control (Junker 2012). Splining is a typical example, where a cogwheel pattern is formed around the shaft end to create the torque transmitting joint. All metal processing requires a continuous spray of "cutting fluid" for cooling and lubrication, this consisting mainly of naphtha diluted in water (Statoil 2015a, b).

Data for steps 8 and 9 was collected from Walter (2015). However, although machinery representative for splining was found at ELMO, no ongoing activity could be used to measure the splining cycle time. Instead, a simple feed rate estimate of $1 \mathrm{~m}$ per minute at a tooth depth of $1 \mathrm{~mm}$ was based on film clip observations for milling in two rounds, one for roughing and one for finishing. It was assumed that doubling the tooth depth would halve the feed rate and vice versa and that each centimeter of diameter allowed for a set of 10 splines around the circumference. All steel scrap losses were accounted for in process 8 , by approximation.

Next, in step 9, the splined section of the shaft requires induction heat treatment to improve its mechanical properties (Tong 2014). The shaft's surface temperature is rapidly raised above $1000{ }^{\circ} \mathrm{C}$ using an induced magnetic field for one or a few seconds only, followed by intensive quenching, using water mixed with an oil- or polymer-based quenching fluid (Rudnev et al. 2014; Tong 2014). The depth of heating required is often only a few millimeters (Rudnev et al. 2014). Energy use data was collected from tabulated values in Haimbaugh (2001). Quenching time, flow, and fluid composition were calculated from several sources (Poteet et al. 2006; Rudnev et al. 2014; Dow 2005a, b, 2014).

In the next activity, process 11 of Fig. 5, taking place in parallel with the preparation of the shaft, rotor core laminations are stacked onto a fixture and magnet segments are placed and fixated within the rotor slot cavities. For premagnetized magnets, automated equipment is difficult to acquire and the procedure used is generally manual (Franke et al. 2011), although efforts have been made to develop new mounting machines (Franke et al. 2011; Franke et al. 2015; Hultman et al. 2014; Tremel et al. 2013). At the same time, large magnets are difficult to handle manually and these have to be mounted in smaller sections. This coincides well with other benefits of segmentation, i.e., reduction of magnet losses. A description of, and the data for, a hand mounting procedure of magnets in IPM rotors was provided by Hendershot (2015). Magnets are delivered in sections and 
rotor laminations are stacked with proper alignment on a fixture up to the same height as magnet length. North Pole magnets are then hand inserted in every other slot, followed by the South Pole magnets being fitted into the remaining slots. The polarity is inspected with a pole detector. The rotor segment is then slightly heated with a hand held heat gun, before the adhesive is applied over each magnet and allowed to trickle down into the small cavities around the magnets. The heat gun is then applied again, from around $30 \mathrm{~s}$ up to a minute, to cure the adhesive. Lastly, the core segments with installed magnets are stacked and aligned on a fixture or directly on the shaft.

Meanwhile, rotor endplates are fabricated, as in process 12 in Fig. 5. Data was gathered from Walter (2015). Endplates are punched from a steel sheet in a stamping machine, similar to the core laminations, but with lower energy use per kilogram of steel. A thick sheet requires a large punching force, but since each plate is punched in one hit, the punch rate is much lower. Parts are then integrated by threading the rotor core onto the shaft and pressing in the endplates to hold everything in place (see step 13 of Fig. 5). According to Walter (2015), the process entails a 20-t force being applied for $5 \mathrm{~s}$. Power consumption information for such pressing was collected from a hydraulic machine from Huahong Technology (2015). Total cycle time was assumed to be double the pressing time, and any leakage of hydraulic oil was neglected. Lastly, the rotor is balanced by removing small amounts of steel from selected points of the endplate through the drilling of minor craters (see process 14 of Fig. 5). This involves two steps, a balance test and drilling, which are repeated until a satisfactory rotor balance has been achieved. Data for this procedure was collected from Walter (2015).

\subsection{Housing parts and final assembly}

Die cast aluminum housing parts are machined at the motor factory before they are ready for final assembly (see process 15 of Fig. 5). Excessive material is removed from the workpiece, and holes or other types of fixation points are prepared. High precision is required for fitting, e.g., the housing body with the stator core and the endbells with the bearings. The tolerance of bearing bores is around $1 \mu \mathrm{m}$ (Walter 2015). This step involves multiple operations, such as turning, cutting, drilling, milling, and threading. Aluminum scrap, mostly shavings, but also dust, is generated, and machined parts have to be blown clean by compressed air spray (see process 16 of Fig. 5).

Data for the preparation of the die cast aluminum parts was collected from ELMO (Karlsson 2013; Walter 2015, 2016) and from Iro AB (Magnusson 2016), another electrical machine manufacturer, in Sweden. Data was gathered in several stages before being compiled: process time was assessed based on the geometrics and surface areas of the parts; the amount of material removed and scrapped per part was established from machining allowances and expert estimations; multi-operation electricity use was gathered from measurements; cutting fluid use was estimated from yearly consumption; and energy for cleaning was extracted from the overall use of compressed air at the plant (Karlsson 2013; Appleton 2016; SWP 2016; Walter 2016).

Next, before the complete housing goes to final assembly, the terminal block is mounted onto the housing body. This operation (number 17 in Fig. 5) was assumed to be manual and without losses. In the end assembly, process 18 , the complete machine is put together in several steps. Most assembly operations are done by hand with support from automated handheld tools, apart from fitting the stator package into the housing body and the bearings onto the shaft. Machine data was gathered for a hydraulic press (Huahong Technology 2015) for the stator fitting and a pneumatic press (driven by the compressed air system of the plant) for the bearing fitting and combined with process settings stated by Walter (2016).

The connector lugs are coupled to the terminal block before all parts are merged into one unit by means of placing the bearings, now joined with the rotor package, into the bores of the endbells. The endbells are then secured to the housing and stator package using the dedicated fasteners. Alongside, the stator part of the resolver is connected to one of the endbells and the rotor part to the end of the shaft. Subsequently, the complete machine goes through a functionality test sequence in a rig. Energy used by the test equipment was accounted for within technical building services.

Finally, in process 19 of Fig. 5, the housing surface is spray-painted with a transparent varnish and the machine set aside to cure at room temperature before delivery. Data for this process was gathered from varnish and solvent suppliers (ExxonMobil 2007, 2014; Von Roll 2013; Larrenduche 2015) and combined with the assessment of the compressed air system and standard spray gun properties (Meiji 2015).

\section{Discussion and conclusions}

New primary LCA inventory data for the manufacturing of an electrical traction machine has been presented. Together with the scalable design model for the motor mass and material configuration, presented in part I of this article series, this forms a comprehensive LCI model of a typical PMSM for automotive electric driving applications.

The new production data includes a unit process for the making of a $\mathrm{Nd}(\mathrm{Dy}) \mathrm{FeB}$ magnet, based on existing LCA data for the NdFeB base body, which was updated and corrected after detailed literature studies, and complemented with patent information for the addition of dysprosium. Furthermore, new LCA data has been presented for the alloy composition of silicon steel and the making of electrical steel based on Swedish steel mill data and expert interviews. Additionally, 
by combining data from various literature sources, new LCA unit process data have been established for the making of electrolytic iron, enameling of copper wire into magnet wire, and die casting of aluminum.

The most detailed survey of production was made for an electric motor factory. Observations from the site visit to ELMO's Swedish motor factory were combined with detailed expert interviews and included procedures at another Swedish plant and a manufacturing facility in Kentucky, USA. Further details were provided mainly by specific plant data and suppliers' machine specifications. The end result is an extensive new dataset representing PMSM manufacturing in large volume.

Accordingly, the generation of the complete LCI model has required a wide-ranging and comprehensive search for raw data. This experience constitutes a good basis for a discussion on data collection methods. In the following, we discuss some of the observations and reflections made during the work.

Most apparent is that these new datasets provide examples of different and complementing strategies to collect LCA data. The acquisition of data for electrical steel production represents one type. This was straightforward and conventional. Although combined from several references, they all originate from the same organization and represent the same facility. However, companies may be unwilling to supply important details, e.g., due to business secrecy. The most sensitive information needed to be obtained was the composition of the silicon steel alloy, especially the specific compositions corresponding to certain grades of electrical steel. This issue was solved by asking for the average composition of all silicon steels used at the steel mill, which in this case was judged to be equally valid and suitable for LCA. But, in other circumstances, process details might be needed to make a production dataset applicable and adjustable for altered product designs. Then, if it is not possible to acquire "single-source" data that is both open and detailed, other methods must be sought.

To give one such example, the main method used for the motor factory was that of "data building," starting from a solid base provided by the site visit and other facility records from ELMO. However, this factory produces electrical machines of another type, not PMSMs. As a consequence, while some parts of the surveyed process flow were unrepresentative, others were missing. In this mapping work, textbooks on manufacturing were used as guides for further in-depth exploration of subject-specific technical publications. Interviews of experts were also extensively used to provide overviews, for engineering estimations, and to assess the representativity of the data collected from technical documentation. A thorough understanding of the product design was found to be important, as production routes are sometimes formed in close link to the design selections. For example, if the stator shall contain a precise and deliberate amount of impregnation material, trickling of resin is much more suitable than dipping the whole stator into varnish. The datasets for magnets, electrolytic iron, enameled wire, and die casted aluminum were generated in a similar approach as in the motor factory, but from various literature sources. The main benefit of the data building approach is that the level of detail can be controlled to make the dataset flexible and relevant. In this project, it was necessary in order to match the scaling of the machine design with the motor factory manufacturing model and correctly account for the function in each production step. An important aspect was the possibility to keep track of multiple output parameters when modeling the process outflows.

Finally, and most importantly, in order to make LCI data possible to criticize, correct, and update, and thereby more broadly applicable, it is essential to report transparent and preferably detailed and disaggregated data records. This is commendably well done in the previously published inventory data by Sprecher et al. (2014a, 2014b) and NETL (2014a), which made the correction and update of their data possible. In contrast, the use of non-transparent and highly aggregated information such as environmental production declarations, which is not uncommon (Habermacher 2011; Weidema et al. 2013; Del Duce et al. 2016; Hernandez et al. 2017), carries the risk of being misleading, since it is impossible to evaluate in terms of relevance.

\section{Future research}

The next step in this project will be to use the model in a full LCA study and exemplify its applicability in the intended context.

\section{Accessing the LCI model file and model report}

The life cycle inventory model file (Nordelöf 2016) and the model report (Nordelöf et al. 2016) can be downloaded from the SPINE database provided by Swedish Life Cycle Center (http://cpmdatabase.cpm.chalmers.se/Scripts/sheet.asp? ActId=JT-2016-06-21-39).

Acknowledgements The authors would like to express their gratitude to the Swedish Electromobility Centre and to the Area of Advance Energy at Chalmers University of Technology for financing the project. We are also deeply grateful to all the data providers, especially Manuel Walter, CEO and owner of ELMO, Malmköpings Mekaniska Werkstad $\mathrm{AB}$, Flen, Sweden.

Open Access This article is distributed under the terms of the Creative Commons Attribution 4.0 International License (http:// creativecommons.org/licenses/by/4.0/), which permits unrestricted use, distribution, and reproduction in any medium, provided you give appropriate credit to the original author(s) and the source, provide a link to the Creative Commons license, and indicate if changes were made. 


\section{References}

ABB (2002) Environmental Product Declaration: AC low voltage cast iron motor, type M3BP 315. ABB Oy/BA Electrical Machines, LV Motors, Vaasa, Finland. (Document code: LV Motors/EPD M3BP315 GB 05-2002 3GZF500931-22)

Althaus H-J, Hischier R, Osses M, Primas A, Hellweg S, Jungbluth N, Chudacoff M (2007) Life cycle inventories of chemicals. 2007: Ecoinvent report no. 8. Swiss Centre for Life Cycle Inventories, Dübendorf (Data v2.0)

Amada Miyachi (2015) Hot crimping. Amada Miyachi Europe Gmbh, Puchheim, Germany (Technical specification for hot crimping/ welding power supply. TDS RW M2-M4 Series RW 01-2015 EN)

Appleton (2016) Air tool or equipment CFM requirement. Appleton Compressor Service \& Supply, Inc http://webtest. appletoncompressor.com/wp-content/uploads/2011/04/Air-Tool-orEquipment-CFM-Requirement.pdf. Accessed 2016-02-08

Arnell S (2012) Principal engineer, ABB Sustainability Reporting, ABB $\mathrm{AB}$, Västerås, Sweden. Personal communication with Greger K. October 31:th, 2012.

Bonvoisin J, Thiede S, Brissaud D, Herrmann C (2013) An implemented framework to estimate manufacturing-related energy consumption in product design. Int J Comput Integr Manuf 26(9):866-880

Brenn G, Steiner H, Baric E (2012) WIRE NEWS 12: high quality wire coating in MAG magnet wire machines. MAG Maschinen- und Apparatebau AG, Austria (Technical information brochure)

Broomfield (2014a) TM-25 trickle impregnation machine. Broomfield Laboratories, United States of America (Machine specification datasheet for electric machine impregnation equipment)

Broomfield (2014b) TM-50 trickle impregnation machine. Broomfield Laboratories, United States of America (Machine specification datasheet for electric machine impregnation equipment)

Brown D, Ma B-M, Chen Z (2002) Developments in the processing and properties of NdFeb-type permanent magnets. J Magn Magn Mater 248(3):432-440

Burress TA, Coomer CL, Campbell SL, Seiber LE, Marlino LD, Staunton RH, Cunningham JP (2008) Evaluation of the 2007 Toyota Camry hybrid Synergy drive system. Olszewski M. Electrical and Electronics Systems Research Division, Oak Ridge National Laboratory, US Department of Energy, USA

Burress TA, Coomer CL, Campbell SL, Wereszczak AA, Cunningham JP, Marlino LD, Seiber LE, Lin HT (2009) Evaluation of the 2008 Lexus LS $600 \mathrm{H}$ hybrid Synergy drive system. Olszewski M. Electrical and Electronics Systems Research Division, Oak Ridge National Laboratory. US Department of Energy, USA

Burress TA, Campbell SL, Coomer CL, Ayers CW, Wereszczak AA, Cunningham JP, Marlino LD, Seiber LE, Lin HT (2011) Evaluation of the 2010 Toyota Prius hybrid Synergy drive system. Olszewski M. Electrical and Electronics Systems Research Division, Oak Ridge National Laboratory. US Department of Energy, USA

Chen SL, Liu W, Geng DY, Zhao XG, Zhang ZD (2006) Decomposition of $\mathrm{B} 4 \mathrm{C}$ and magnetic properties of $\mathrm{Nd}-\mathrm{Fe}-(\mathrm{B}, \mathrm{C})$ alloys synthesized by mechanical alloying. J Alloy Compd 415(1-2):271-275

Classen M, Althaus H-J, Blaser S, Scharnhorst W, Tuchschmid M, Jungbluth N, Emmenegger MF (2009) Life cycle inventories of metals. March, 2009: Ecoinvent report No. 10. Swiss Centre for Life Cycle Inventories, Dübendorf, Switzerland. (Data v2.1)

Croat JJ (1992) High energy product rare earth magnet alloys. United States of America Patent

Czaputa K (2012) WIRE NEWS 12: the serious idea behind the incredible Mozart zero. MAG Maschinen- und Apparatebau AG, Austria (Technical information brochure)

Dalquist S, Gutowski T (2004) Life cycle analysis of conventional manufacturing techniques: die casting. December, 2004: LMP-
MIT-TGG-03-12-09-2004. In: Environmentally benign manufacturing group, Laboratory for Manufacturing and Productivity. Massachusetts Institute of Technology, Boston http://web.mit.edu/ ebm/www/publications

Del Duce A, Gauch M, Althaus H-J (2016) Electric passenger car transport and passenger car life cycle inventories in ecoinvent version 3. Int J Life Cycle Assess 21:1314-1326

Dow (2005a) Selection guide for UCON quenchants. The Dow Chemical Company, United States of America (Guide for the use of $\mathrm{UCON}^{\mathrm{TM}}$ quenchants during steel hardening. Form No. 118-01588-1005)

Dow (2005b) UCON ${ }^{\mathrm{TM}}$ Quenchant RL. The Dow Chemical Company, United States of America (Technical data sheet $\mathrm{UCON}^{\mathrm{TM}}$ Quenchant RL. Form No. 118-01291-0205-rlr)

Dow (2014) Product safety assessment-UCON ${ }^{\mathrm{TM}}$ Quenchants and metalworking lubricants. The Dow Chemical Company, United States of America (Product safety description for $\mathrm{UCON}^{\mathrm{TM}}$ quenchants. Form No. 233-000808-MM-0614X)

ExxonMobil (2007) Material safety data sheet: aromatic 100 fluid. Exxon Mobil Corporation, United States of America (Product MSDS)

ExxonMobil (2014) Product safety summary: aromatic 100 fluid; Solvesso $^{\text {TM }} 100$ fluid. Exxon Mobil Corporation, United States of America (Product safety datasheet)

Fang ZZ (ed) (2010) Sintering of advanced materials - fundamentals and processes. Woodhead Publishing Limited, Cambridge

Franke J, Tremel J, Kuhl A (2011) Innovative developments for automated magnet handling and bonding of rare earth magnets. Paper presented at the assembly and manufacturing (ISAM), 2011 I.E. International Symposium on, Tampere, Finland, 25-27 May.

Franke J, Hofmann B, Tremel J, Meyer A Innovative methods for automated assembly and fixation of permanent magnets in electrical machines. In: 12th Global Conference on Sustainable Manufacturing, Johor Bahru, Malaysia, 22-24 September, 2014 2015. pp 724-728. doi:10.1016/j.procir.2014.07.066

Ghosh A (2000) Secondary steelmaking: principles and applications. CRC Press, United States of America

Gutowski T, Dahmus J, Thiriez A (2006) Electrical energy requirements for manufacturing processes. Paper presented at the 13th CIRP International Conference of Life Cycle Engineering, Lueven, Belgium, May 31:st-June 2:nd

Habermacher F (2011) Modeling material inventories and environmental impacts of electric passenger cars. Master Thesis, Department of Environmental Sciences, ETH Zurich, Switzerland

Haimbaugh RE (2001) Practical induction heat treating. ASM International, Materials Park, Ohio

Hawkins T, Gausen O, Strømman A (2012) Environmental impacts of hybrid and electric vehicles - a review. Int J Life Cycle Assess 17(8):997-1014

Heinemann T (2016) Energy and resource efficiency in aluminium die casting. Sustainable production, life cycle engineering and management. Springer International Publishing, Switzerland

Hendershot JR (2015) President \& CEO of Motorsolver LCC, SAE \& ASME member, IEEE life fellow. Personal communication with Nordelöf A. December 26:th, 2015

Hernandez M, Messagie M, Hegazy O, Marengo L, Winter O, Mierlo J (2015a) Electronic Supplementary Material - environmental impact of traction electric motors for electric vehicles applications. Vrije Universiteit Brussel, Faculty of Engineering, Mobility and Automotive Technology Research Group (MOBI), Brussels, Belgium (Supplementary Material for the International Journal of Life Cycle Assessment)

Hernandez M, Messagie M, Hegazy O, Marengo L, Winter O, Mierlo J (2015b-2017) Environmental impact of traction electric motors for electric vehicles applications. Int J Life Cycle Assess 22:55-65

Hischier R (2007) Life cycle inventories of packagings and graphical papers. - part II, plastics. 2007: Ecoinvent report no. 11. Swiss Centre for Life Cycle Inventories, Dübendorf (Data v2.0) 
Huahong Technology (2015) Q43-1200A. Jiangsu Huahong Technology Stock Co., Ltd. http://www.asiabaler.com/Q43.php. Accessed 2016-02-05

Hultman E, Salar D, Leijon M (2014) Robotized surface mounting of permanent magnets. Mach Des 2(4):219

IPPC (2001) Integrated Pollution Prevention and Control (IPPC)—best available techniques reference document on the production of iron and steel. December, 2001. European Commission

Johansson J (2015) Technical Specialist Power Electronics, Volvo Group Trucks Technology, Volvo Group. Personal communication with Nordelöfa. April 9:th, 2015

Junker S Highly flexible and efficient shaft manufacture for customized electric machines. In: Electric Drives Production Conference (EDPC), 2012 2nd International, 15-18 Oct. 2012 2012. pp 1-4. doi:10.1109/EDPC.2012.6425094

Karlsson P (2013) Mätning vid Malmköpings Mekaniska Werkstad AB. Industriell Laststyrning. (Measurement charts for energy and power consumption as part of an energy survey at Malmköpings Mekaniska Werkstad AB)

Koltun P, Tharumarajah A (2014) Life cycle impact of rare earth elements. ISRN Metall 2014:10. doi:10.1155/2014/907536

Låftman L (2012) Senior technical specialist of electric motors, Danaher Motion Stockholm AB/Kollmorgen Corporation; Danaher Corporation. Personal communication with Greger K. November $11:$ th, 2012

Lagneborg R, Waltersson E (2004) Guide för legeringsmetaller och spårelement i stål, 2nd edn. Jernkontoret, Stockholm

Lahd Geagea M, Stille P, Gauthier-Lafaye F, Millet M (2008) Tracing of industrial aerosol sources in an urban environment using $\mathrm{Pb}, \mathrm{Sr}$, and $\mathrm{Nd}$ isotopes. Environ Sci Technol 42(3):692-698

Larrenduche D (2015) Global Product Line Manager, Vice President Product Line Management, Von Roll Isola France SA. Personal communication with Nordelöf A. September 5:th and 7:th, and October 28:th, 2015.

Leoni (2014) LEONI automotive cables. Leoni Kabel GmbH, Germany (Product catalogue for automotive cables)

Lewis CJ, Boynton RS (1999) Acid neutrilization with lime for environmental control and manufacturing processes. The National Lime Association, United States of America

Li WF, Sepehri-Amin H, Ohkubo T, Hase N, Hono K (2011) Distribution of Dy in high-coercivity (Nd,Dy)-Fe-B sintered magnet. Acta Mater 59(8):3061-3069

Lindenmo M (2012) Manager development and technical customer support, Cogent Power/Surahammars Bruk AB. Personal communication with Greger K. December 4:th, 2012

Lindenmo M (2015) Manager Development and Technical Customer Support, Cogent Power/Surahammars Bruk AB. Personal communication with Nordelöf A. June 21:st and 25:th, and August 21:st, 2015

Liu NC, Stadelmaier HH (1986) High coercivity permanent magnet materials based on iron-rare-earth-carbon alloys. Mater Lett 4(8-9): 377-380

Lucas J, Lucas P, Le Mercier T, Rollat A, Davenport WGI (2015) Rare earths - science, technology. Production and Use Elsevier B.V, Amsterdam

MAG (2016) Mozart Zero H5 - horizontal single line copper wire enamelling machine. MAG Maschinen- und Apparatebau AG. http:// www.mag.at/products/horizontal-machines/Mozart-H5.php. Accessed 2016-02-23

Magnusson P (2016) Product manager, mechanics, at IRO AB, van de Wiele Group, Ulricehamn, Sweden. Personal communication with Nordelöf a. February 9:th, 2016

McCallum RW, Branagan DJ (1996) Carbide/nitride grain refined rare earth-iron-boron permanent magnet and method of making. United States of America Patent
Meiji (2015) Spray gun painting equipment. Meiji Air Compressor MFG CO., LTD., Japan (Product catalogue for air spray painting equipment. Catalog number $151002 \mathrm{KS}$ )

Moing A, Vardelle A, Legoux JG, Themelis NJ (2009) LCA comparison of electroplating and other thermal spray processes. In: Paper presented at the thermal spray 2009: expanding thermal spray performance to new markets and applications. ASM International, Las Vegas

Nagasaki Y, Shimao M (2015) Production method for rare earth permanent magnet. United States of America Patent

NETL (2014a) NETL life cycle inventory data-unit process: NdFeB permanent magnet manufacturing [online]. Last updated: July 3 2014. Version 01. United Stated of America: U.S. Department of Energy, National Energy Technology Laboratory. Available: www. netl.doe.gov/LCA. Accessed October 292015 (Gate-to-gate manufacturing process for $1 \mathrm{~kg}$ plated $\mathrm{NdFeB}$ permanent magnet)

NETL (2014b) NETL life cycle inventory data-unit process: rare earth oxide electrolysis [online]. Last updated: June 5 2014. Version 01. United Stated of America: U.S. Department of Energy, National Energy Technology Laboratory. Available: www.netl.doe.gov/ LCA. Accessed October 292015 (Gate-to-gate process - electrolysis of a rare earth oxide using a fluoride-based process)

NETL (2015) NETL Unit Process Library. U.S. Department of Energy, National Energy Technology Laboratory. http://www.netl.doe.gov/ research/energy-analysis/life-cycle-analysis/unit-process-library. Accessed October 292015

Ningbo Haishu Nide (2014) Varnish machine catalogue. Ningbo Haishu Nide International Co., Ltd., China (Product catalogue for electric machine impregnation equipment)

Ningbo Nide (2014) Induction machine catalogue. Ningbo Nide Mechanical Equipment Co., Ltd., China (Product catalogue for electric machine manufacturing equipment)

Nordelöf A (2016) Scalable IPMSM LCI Model.xlsm [online]. Version 1.0. Gothenburg, Sweden: Environmental Systems Analysis; Chalmers University of Technology. Distributed by The Swedish Life Cycle Center. Available: http://cpmdatabase.cpm.chalmers.se/ Scripts/sheet.asp?ActId=JT-2016-06-21-39 (Gate to gate life cycle inventory in Microsoft Excel Macro-Enabled Worksheet)

Nordelöf A, Messagie M, Tillman A-M, Ljunggren Söderman M, Van Mierlo J (2014) Environmental impacts of hybrid, plug-in hybrid, and battery electric vehicles - what can we learn from life cycle assessment? Int J Life Cycle Assess 19(11):1866-1890

Nordelöf A, Grunditz E, Tillman A-M, Thiringer T, Alatalo M (2016) A scalable life cycle inventory of an electrical automotive traction machine-technical and methodological description, version 1.0.2016: report no. 2016:4. Department of Energy and Environment, Divisions of Environmental Systems Analysis \& Electric Power Engineering, Chalmers University of Technology, Gothenburg

Nuss P, Eckelman MJ (2014) Life cycle assessment of metals: a scientific synthesis. PLoS One 9(7):12

Oeters F, Ottrow M (2012) Production of pure and high purity iron. Ullmann's encyclopedia of industrial chemistry, vol 20. Wiley$\mathrm{VCH}$ Verlag $\mathrm{GmbH} \& \mathrm{Co}$, Weinheim

Överstam U (2013) LCA Scientist, ABB AB Corporate Research, ABB $A B$, Västerås, Sweden. Personal communication with Greger K. and Nordelöf A. February 20:th and March 7:th, 2013

Polynt Composites (2015) Polymac 220-1935. Polynt Composites USA, Inc, USA (Technical specification for thermosetting polyester resin intended for coil coating)

Poteet D, Totten GE, Canale LCF (2006) Basic principles of quench system design for induction hardening. In: Herring D (ed) Heat Treating: proceedings of the 23 rd heat Treating society Conference, David L. Lawrence convention Center, Pittsburgh, Pennsylvania, USA, September 25-28, 2005 2006. ASM International, Materials Park, $\mathrm{OH}$ 
Richnow J, Stenzel P, Renner A, Gerling D, Endisch C Influence of different impregnation methods and resins on thermal behavior and lifetime of electrical stators. In: 4:th International Electric Drives Production Conference (EDPC), 2014 Sept. 30-Oct. 1 2014 2014. pp 1-7. doi:10.1109/edpc.2014.6984406

Roberts MJ (2003) Modified life cycle inventory of aluminium die casting. Deakin University, Victoria

Rudnev V, Fett GA, Griebel A, Tartaglia J (2014) Principles of induction hardening and inspection. In: Rudnev V, Totten GE (eds) ASM handbook, induction heating and heat treatment, vol 4C. ASM International, $\mathrm{p} 820$

Schlesinger M, Paunovic M (eds) (2010) Modern electroplating, 5th edn. John Wiley \& Sons, Ltd., Hoboken

Sprecher B, Xiao Y, Walton A, Speight J, Harris R, Kleijn R, Visser G, Kramer GJ (2014a) Life cycle inventory of the production of rare earths and the subsequent production of $\mathrm{NdFeB}$ rare earth permanent magnets. Environ Sci Technol 48(7):3951-3958

Sprecher B, Xiao Y, Walton A, Speight J, Harris R, Kleijn R, Visser G, Kramer GJ (2014b) Life cycle inventory of the production of rare earths and the subsequent production of $\mathrm{NdFeB}$ rare earth permanent magnets - supporting information. Institute of Environmental Sciences (CML), Leiden University, The Netherlands (Supporting Information for Environmental Science \& Technology)

Statoil (2015a) Produktdatablad Coolway HD 25. Statoil Fuel and Lubricants Sweden AB, Sweden (Cutting fluid technical specification)

Statoil (2015b) Säkerhetsdatablad: COOLWAY HD 25. Statoil Fuel \& Retail Lubricants Sweden AB, Sweden (Cutting fluid MSDS)

Steiner R, Frischknecht R (2007) Metals processing and compresses air supply. 2007: Ecoinvent report no. 23. Swiss Centre for Life Cycle Inventories, Uster, Switzerland (Data v2.0)

Suppan G, Ruehrig M, Kanitz A, Gores HJ (2015) Electroplating dysprosium from IL-based solutions: a promising electrochemical step to produce stronger high performance $\mathrm{Nd}(\mathrm{Dy})-\mathrm{Fe}-\mathrm{B}$ sintered magnets. J Electrochem Soc 162(8):D382-D388

SWP (2016) Air tool consumption guide. Specialised Welding Products Ltd. http://www.specialisedwelding.co.uk/manuals/Air Compressor_Manuals/Air\%20Tool\%20Consumption\%20Guide. pdf. Accessed 2016-02-08

TES Vsetín (2015) Hot crimping. TES Vsetín s.r.o, Czech Republic (Technical catalogue for hot crimping system)

The National Lime Association (2015) Iron and steel. Creativo Inc. http:// www.hitachi-chem.co.jp/english/products/eim/001.html. Accessed 29 July 2015
Tong W (2014) Mechanical design of electric motors. CRC Press, Taylor \& Francis Group, Boca Raton

Tremel J, Hofmann B, Risch F (2013) Handling and fixation of permanent magnets. Adv Mater Res 769:3-10

US EPA (2012) Rare earth elements: a review of production, processing, recycling, and associated environmental issues. December, 2012: EPA 600/R-12/572. The U.S. Environmental Protection Agency (EPA), Office of Research and Development, Cincinnati, $\mathrm{OH}$

Vaimann T, Kallaste A, Kilk A, Belahcen A Magnetic properties of reduced Dy NdFeB permanent magnets and their usage in electrical machines. In: AFRICON, 2013, 9-12 Sept. 2013. pp 1-5. doi:10. 1109/AFRCON.2013.6757787

Vanadium AMG (2015) Silicon. AMG Vanadium Inc. http://amg-v.com/ siliconpage.html. Accessed 21 May 2015

Volvo (2015) Volvo Electric Concept Bus. Volvo Bus Corporation, Sweden (Product datasheet for Volvo's all electric concept bus, BED 00685.15.05 SE)

Von Roll (2013) Varnish-Damicoat® 2405-2 natural. Von Roll France SA, France (Product datasheet)

Walter M (2015) CEO and owner, ELMO, Malmköpings Mekaniska Werkstad AB, Flen, Sweden. Personal communication with Nordelöf A. August 27:th, October 10:th and November 4:th, 2015.

Walter M (2016) CEO and owner, ELMO, Malmköpings Mekaniska Werkstad AB, Flen, Sweden. Personal communication with Nordelöf A. January 29:th, and February 2:nd and 8:th, 2016

Weidema BP, Bauer C, Hischier R, Mutel C, Nemecek T, Reinhard J, Vadenbo CO, Wernet G (2013) The ecoinvent database: Overview and methodology, Data quality guideline for the ecoinvent database version 3. The Centre for Life Cycle Inventories. www.ecoinvent. org. 2014-2016

Willard S (2015) Sales Manager at Broomfield Laboratories. Personal communication with Nordelöf A. December 18:th, 2015

Xue A (2015) Marketing \& Sales Manager at Ningbo Nide Mechanical Equipment Co., Ltd. Personal communication with Nordelöf A. December 17:th, 2015

Yan G, McGuiness PJ, Farr JPG, Harris IR (2010) Optimisation of the processing of $\mathrm{Nd}-\mathrm{Fe}-\mathrm{B}$ with dysprosium addition. J Alloy Compd 491(1-2):L20-L24

Zakotnik M, Tudor CO (2015) Commercial-scale recycling of NdFeBtype magnets with grain boundary modification yields products with 'designer properties' that exceed those of starting materials. Waste Manag 44:48-54 